Int. J. Electrochem. Sci., 14 (2019) $6748-6758$

\title{
Simultaneous Determination of Acetaminophen and Tyrosine Using Screen-printed Electrochemical Sensor Based on MWCNTs-doped Poly(glycine)/Poly(acrylic acid) Conducting Polymers
}

\author{
Zhiqiang Wei ${ }^{1}$, Shaofang Guo $^{2}$, Liuyang Cheng ${ }^{1}$, Ting Li ${ }^{1}$, Yanli Zhang ${ }^{1}$, Hui Yang ${ }^{1, *}$ \\ ${ }^{1}$ College of Medical, Henan University of Science and Technology, Luoyang, 471023, China. \\ ${ }^{2}$ Hospital of Henan University of Science and Technology, Luoyang, 471023, China. \\ *E-mail: yanghui7761@163.com
}

doi: $10.20964 / 2019.07 .26$

Received: 5 February 2019 / Accepted: 26 April 2019 / Published: 10 June 2019

\begin{abstract}
A sensitive electrochemical sensor for the simultaneous determination of acetaminophen (ACOP) and tyrosine (Tyr) was proposed based on MWCNTs-doped poly (glycine) (p-gly)/ poly (acrylic acid) (PAA) conducting polymers modified screen-printed electrode (SPE). The incorporation of MWCNTs and pgly/ PAA composite conductive polymers brought about enhanced electro-catalytic activity and additional binding sites for ACOP and Tyr. Cyclic voltammetry (CV) and linear sweep voltammetry (LSV) were performed to investigate the electrochemical behaviors of ACOP and Tyr. Under the optimal experimental conditions, the oxidation peak currents of ACOP and Tyr increased linearly with two concentration intervals over the range of $0.25-120 \mu \mathrm{M}$ and $0.4-150 \mu \mathrm{M}$, respectively. The detection limits $(\mathrm{S} / \mathrm{N}=3)$ were $0.08 \mu \mathrm{M}$ for ACOP and $0.13 \mu \mathrm{M}$ for Tyr. Moreover, the sensor has been successfully applied for the determination of ACOP and Tyr in human serum samples, showing its great application prospects in pharmaceutical analysis.
\end{abstract}

Keywords: Screen-printed Electrode, Poly (glycine), Poly (acrylic acid), Acetaminophen, Tyrosine

\section{$\underline{\text { FULL TEXT }}$}

(C) 2019 The Authors. Published by ESG (www.electrochemsci.org). This article is an open access article distributed under the terms and conditions of the Creative Commons Attribution license (http://creativecommons.org/licenses/by/4.0/). 